\title{
Dosimetric Comparison of Radiotherapy Techniques for Treating Early-stage Glottic Larynx Cancer
}

\author{
Tanju Berber ${ }^{1}$ (), Birhan Demirhan2 \\ ${ }^{1}$ istanbul Okmeydanı Training and Research Hospital, Clinic of Radiation Oncology, İstanbul, Turkey \\ ${ }^{2}$ Van Regional and Training Hospital, Clinic of Radiation Oncology, Van, Turkey
}

Cite this article as: Berber T, Demirhan B. The Retrospective Evaluation of The Local Tumor Control and Adverse Effects of Treatment in Patients Treated Using Cyberknife Stereotactic Radiotherapy in Vestibular Schwannomas. JAREM 2020;10(1): 16-22

\begin{abstract}
Objective: As early-stage larynx carcinoma is considered curable, we have investigated the possible differences among treatments with the contribution of advanced technology for maximum prevention of the development of secondary malignancies, and for the long-term quality of life. We compared the doses to the organs at risk, the Conformity indexes $(\mathrm{Cl})$, and the total monitor units of patients with early-stage glottic laryngeal cancer with the patients' physical planning for 3-dimensional conformal radiotherapy (3DCRT), intensity-modulated radiotherapy (IMRT), and volumetric modulated arc radiotherapy (VMAT) using the Eclipse treatment planning system.

Methods: Radiotherapy planning tomography sections of patients with early-stage (T1NOMO) glottic larynx cancer who underwent only radiotherapy were used. The sections were used for target volume and critical organ descriptions. Plans for 3DCRT, VMAT, 5-field IMRT, and 7-field IMRT were made and were compared after the procedures. The patients did not receive elective nodal irradiation. A total of 63 Gy in 28 fractions was described for all patients for the planning target volume (PTV).

Results: There was no difference between the mean PTV dose for VMAT and 5-field and 7-field IMRT. VMAT had the best results for the heterogeneity index and $\mathrm{Cl}_{\text {; }}$ 7-field IMRT had the best results for the mean dose and carotid artery volume receiving (V35 Gy) values. Although very low doses were detected for the medulla spinalis for 3DCRT, the doses of the other three plans were acceptable.

Conclusion: Due to the higher conformality and better protection of the critical organs, VMAT or IMRT is more appropriate rather than 3DCRT in RT treatment of early-stage glottic larynx cancer. The use of 7-field IMRT yields positive results, particularly for the carotid arteries.
\end{abstract}

Keywords: Dosimetric comparison, early-stage glottic larynx cancer, volumetric arc radiotherapy, intensity-modulated radiotherapy

\section{INTRODUCTION}

Larynx cancer constitutes $2 \%$ of all cancers and is the second most common cancer after skin cancer in the head-neck region (1). Tobacco use greatly influences the development of larynx cancer (2). Larynx cancers are most frequently detected in the glottic region. The primary treatment of early-stage glottic larynx cancer is surgical treatment or radiotherapy (RT). RT is a singly performed primary treatment in early-stage glottic larynx cancer. It has the advantages of organ protection and enables better voice quality compared to the surgical treatment (3-6). Recently, there has been increased use and preference for treatments that enable larynx protection with increased quality of life. Owing to the functional importance of the larynx, completing treatment with minimal function loss in cancer control has become one of the most important treatment targets $(7,8)$. Factors such as anterior commissure involvement, tumor field size, daily fraction and total dose, total treatment time, beam energy, male gender, and pretreatment hemoglobin level determine the tumor control of RT in larynx cancer (9-11). RT causes acute and chronic toxicities based on the treated region. To decrease these toxicities, RT for treating

ORCID IDs of the authors: T.B. 0000-0002-4087-4760; B.D. 0000-0002-3551-9000 
The carotid arteries (right and left), medulla spinalis, and thyroid gland were contoured as the organs at risk (OAR). The medulla spinalis and carotid arteries were drawn in the space determined via the addition of $1 \mathrm{~cm}$ to the upper and lower borders of the PTV. The thyroid gland was described to involve the entire organ. In addition, the body sections outside the PTV receiving doses of 5 Gy (D5) and $>5$ Gy were described. Four plans were prepared using the RapidArc Millennium 120 MLC device on the Eclipse 10.0 system to provide $63 \mathrm{~Gy} / 28$ fractions to all of the patients. The 3DCRT used two opposite lateral fields; IMRT planning used 5- and 7-field techniques; VMAT planning used the double arc method. All plans used a 6-MV photon beam. The data were obtained using dose-volume histograms.

\section{Statistical Analysis}

The data were prepared using the Microsoft Excel 2013 program. We compared the OAR doses; total treatment times; tumor dose coverage; Conformity index (Cl); Homogeneity index (HI); total monitor units administered; and the low, median, and high dose volumes of the normal tissues rather than the target volume among the four dosimetric plans. The statistical analyses were performed using the SPSS 22 program.

\section{RESULTS}

\section{Target Volume Dose Contents}

The PTV63 volume levels were between 71.4 and $89.3 \mathrm{~mL}$ (mean: $77.4 \mathrm{~mL}$ ). There was a statistically significant difference between the mean PTV and mean dose measurements of the RT techniques $(p=0.003)$.

The mean PTV and D5 (Gy) of VMAT was significantly lower than that of 5-field IMRT ( $p=0.000)$, 7-field IMRT ( $p=0.000)$, and 3DCRT $(p=0.000)(p<0.05)$. There was no statistically significant difference between the mean PTV and D5 (Gy) of 5-field IMRT and 7-field IMRT $(p>0.05)$. There was no statistically significant difference between the mean PTV and D5 (Gy) measurements $(p=0.837)$. There was a statistically significant difference between the mean PTV of the methods and the $H I(p=0.001)$ and between the mean PTV and the $\mathrm{Cl}$ of the methods $(p=0.001)$ (Table 1, 2).

\section{Doses in Organs at Risk}

The carotid arteries, medulla spinalis, and thyroid gland involved in the treatment region were described as the OAR and were evaluated.

\section{Carotid Arteries}

The mean carotid artery doses and the mean dose measurements were statistically significantly different $(p=0.001)$.

There was a statistically significant difference between the mean carotid artery dose and minimum dose (Gy) measurements $(p=0.001)$. Paired comparisons showed that the mean carotid artery dose and the minimum dose (Gy) of 3DCRT were significantly higher than those of VMAT $(p=0.000)$, 5 -field IMRT $(p=0.000)$, and

Dose: 63 Gy/28 fractions. 
7-field IMRT $(p=0.000)(p<0.05)$. The mean carotid artery dose and the minimum dose (Gy) of VMAT were significantly higher than those of 7-field IMRT $(p=0.003)(p<0.05)$. The mean carotid artery dose and minimum dose (Gy) of the 5-field IMRT and 7-field IMRT were not statistically significantly different $(p>0.05)$. The mean carotid artery dose and the minimum dose (Gy) of the 5-field IMRT and VMAT were not statistically significantly different $(p>0.05)$.

There was a statistically significant difference between the mean carotid artery dose and the maximum dose (Gy) measurements of the RT techniques $(p=0.001)$. Paired comparisons demonstrated that the mean carotid artery dose and the maximum dose (Gy) measurement of 3DCRT were significantly higher than those of VMAT $(p=0.000)$, 5-field IMRT $(p=0.019)$, and 7-field IMRT $(p=0.000)(p<0.05)$.

There was a statistically significant difference between the mean carotid artery dose and the V35 ( $\mathrm{cm}^{3}$, volume receiving $\left.35 \mathrm{~Gy}\right)$ measurements $(p=0.001)$ and between the mean carotid artery dose and the V50 $\left(\mathrm{cm}^{3}\right)$ measurements $(p=0.001)$ of the RT techniques (Table 3, 4).

Table 1. The evaluation of the planning target volume measurements

\begin{tabular}{|c|c|c|c|c|c|}
\hline & VMAT & IMRT 5-field & IMRT 7-field & 3DCRT & \\
\hline & Mean \pm SD & Mean \pm SD & Mean \pm SD & Mean \pm SD & P \\
\hline PTV - mean dose & $65.14 \pm 0.74$ & $65.52 \pm 0.2$ & $65.51 \pm 0.27$ & $66 \pm 0.56$ & ${ }^{1} 0.003^{*}$ \\
\hline PTV - D5 (Gy) & $66.41 \pm 0.41$ & $67.26 \pm 0.18$ & $67.17 \pm 0.32$ & $67.88 \pm 0.49$ & ${ }^{1} 0.001$ * \\
\hline PTV - D95 (Gy) (median) & $62.95 \pm 0.06(63)$ & $62.97 \pm 0.05(63)$ & $62.96 \pm 0.05(63)$ & $62.96 \pm 0.05(63)$ & ${ }^{2} 0.837$ \\
\hline PTV - HI (median) & $0.047 \pm 0.007(0.05)$ & $0.061 \pm 0.005(0.06)$ & $0.059 \pm 0.005(0.06)$ & $0.068 \pm 0.009(0.07)$ & ${ }^{2} 0.001$ * \\
\hline PTV - Cl (median) & $0.97 \pm 0.05(1)$ & $1.21 \pm 0.13(1.2)$ & $1.27 \pm 0.16(1.2)$ & $2.22 \pm 0.31(2.2)$ & ${ }^{20} 0.001$ * \\
\hline
\end{tabular}

VMAT: Volumetric modulated arc radiotherapy, IMRT: intensity-modulated radiotherapy, DCRT: dimensional conformal radiotherapy, PTV: planning target volume, SD: standard deviation, HI: Heterogeneity index, Cl: Conformity index

Table 2. The evaluation of the compatibility of planning target volume measurements to the plans

\begin{tabular}{|c|c|c|c|c|c|c|}
\hline & $\begin{array}{l}\text { VMAT/IMRT } \\
\text { 5-field }\end{array}$ & VMAT/IMRT 7-field & VMAT/3DCRT & $\begin{array}{l}\text { IMRT-5 field/ } \\
\text { IMRT-7 field }\end{array}$ & $\begin{array}{l}\text { IMRT } \\
\text { 5-field/3DCRT }\end{array}$ & $\begin{array}{l}\text { IMRT } \\
\text { 5-field/3DCRT }\end{array}$ \\
\hline${ }^{1} \mathrm{PTV}$ - mean dose & 0.378 & 0.210 & $0.002^{*}$ & 1.000 & $0.022^{\star}$ & $0.004^{*}$ \\
\hline 'PTV - D5 (Gy) & $0.000^{\star}$ & $0.000^{*}$ & $0.000^{*}$ & 1.000 & $0.000^{*}$ & $0.000^{*}$ \\
\hline 2PTV - HI (median) & $0.000^{\star}$ & $0.000^{*}$ & $0.000^{*}$ & 0.157 & $0.007^{\star}$ & $0.000^{*}$ \\
\hline${ }^{2} \mathrm{PTV}$ - Cl (median) & $0.000^{*}$ & $0.000^{*}$ & $0.000^{*}$ & 0.221 & $0.000^{*}$ & $0.000^{*}$ \\
\hline
\end{tabular}

VMAT: Volumetric modulated arc radiotherapy, IMRT: intensity-modulated radiotherapy, DCRT: dimensional conformal radiotherapy, PTV: planning target volume, HI: Heterogeneity index, Cl: Conformity index

Table 3. The evaluation of the measurements of the carotid artery

\begin{tabular}{l|l|l|l|l|l} 
& VMAT & IMRT 5-field & IMRT 7-field & 3DCRT & P \\
\hline & Mean \pm SD & Mean \pm SD & Mean \pm SD & Mean \pm SD \\
\hline Carotid artery - mean dose & $32.69 \pm 3.79$ & $35.51 \pm 5.58$ & $29.2 \pm 3.72$ & $61.99 \pm 1.30$ \\
\hline Carotid artery - min dose (Gy) & $4.53 \pm 0.51$ & $4.45 \pm 0.96$ & $4.09 \pm 0.46$ & $26.16 \pm 4.14$ & $0.001^{*}$ \\
\hline Carotid artery - max dose (Gy) & $64.59 \pm 1.51$ & $66.84 \pm 1.01$ & $65.78 \pm 1.04$ & $67.73 \pm 0.81$ \\
\hline Carotid artery - V35 $\left(\mathrm{cm}^{3}\right)$ & $3.47 \pm 1.16$ & $3.98 \pm 1.54$ & $3.14 \pm 0.84$ & $7.74 \pm 1.62$ & $0.001^{*}$ \\
\hline Carotid artery - V50 $\left(\mathrm{cm}^{3}\right)$ & $1.11 \pm 0.57$ & $1.7 \pm 1.38$ & $1.01 \pm 0.34$ & $7.11 \pm 1.6$ & $0.001^{*}$ \\
\hline VMAT: Volumetric modulated arc radiotherapy, IMRT: intensity-modulated radiotherapy, DCRT: dimensional conformal radiotherapy, SD: standard deviation
\end{tabular}

Table 4. The evaluation of the compatibility of the carotid artery measurements to the plans

\begin{tabular}{|c|c|c|c|c|c|c|}
\hline & $\begin{array}{l}\text { VMAT/ IMRT } \\
5 \text {-field }\end{array}$ & $\begin{array}{l}\text { VMAT/ IMRT } \\
\text { 7-field }\end{array}$ & $\begin{array}{l}\text { VMAT/ } \\
\text { 3DCRT }\end{array}$ & $\begin{array}{l}\text { IMRT 5-field/ } \\
\text { IMRT 7-field }\end{array}$ & $\begin{array}{l}\text { IMRT 5-field/ } \\
\text { 3DCRT }\end{array}$ & $\begin{array}{l}\text { IMRT 5-field/ } \\
\text { 3DCRT }\end{array}$ \\
\hline Carotid artery - mean dose & 0.297 & $0.034^{*}$ & $0.000^{\star}$ & $0.000^{*}$ & $0.000^{\star}$ & $0.000^{*}$ \\
\hline Carotid artery - min dose (Gy) & 1.000 & $0.003^{*}$ & $0.000^{\star}$ & 0.321 & $0.000^{*}$ & $0.000^{*}$ \\
\hline Carotid artery - max dose (Gy) & $0.000^{\star}$ & $0.033^{*}$ & $0.000^{*}$ & 0.065 & $0.019^{*}$ & $0.000^{*}$ \\
\hline Carotid artery - V35 $\left(\mathrm{cm}^{3}\right)$ & 0.111 & 0.765 & $0.000^{\star}$ & $0.020^{\star}$ & $0.000^{\star}$ & $0.000^{*}$ \\
\hline Carotid artery - V50 $\left(\mathrm{cm}^{3}\right)$ & 0.137 & 1.000 & $0.000^{*}$ & 0.172 & $0.000^{*}$ & $0.000^{*}$ \\
\hline
\end{tabular}




\section{Thyroid Gland and Medulla Spinalis}

There was a statistically significant difference between the mean thyroid gland dose and the mean dose measurements of the RT techniques $(p=0.001)$. Paired comparisons showed that the mean thyroid gland dose and the mean dose of 3DCRT were significantly higher than those of VMAT $(p=0.000)$, 5-field IMRT $(p=0.000)$, and 7-field IMRT $(p=0.000)(p<0.05)$. There was no statistically significant difference between the mean thyroid gland dose and the mean dose measurements of VMAT, 5-field IMRT, and 7-field IMRT ( $p>0.05)$.

There was a statistically significant difference between the mean medulla spinalis dose and the maximum dose measurements of the RT techniques $(p=0.001)$. Paired comparisons showed that the mean medulla spinalis dose and the maximum dose of 3DCRT were significantly lower than those of VMAT $(p=0.000)$, 5-field IMRT $(p=0.000)$, and 7-field IMRT $(p=0.000)(p<0.05)$. There was no statistically significant difference between the mean medulla spinalis dose and the maximum dose of VMAT, 5-field IMRT, and 7-field IMRT ( $p>0.05)$ (Table 5, 6).

\section{Organs at Risk Outside the Planning Target Volume}

Evaluation of the low and median doses of normal tissues outside the PTV63 exposed to radiation revealed a significant difference for V5, V10, V20, V30, and V40 (Table 7).

\section{Monitor Unit Values}

There was a statistically significant difference between the mean monitor unit measurements of the RT techniques ( $p=0.001)$. As expected, the mean monitor unit values of the 3DCRT plans were significantly lower than those of the VMAT, 5-field IMRT, and 7-field IMRT plans (Table 8).

\section{Treatment Times}

There was a statistically significant difference in the mean treatment times of the RT techniques $(p=0.001)$. The mean treatment time of the VMAT, 5-field IMRT, 7-field IMRT, and 3DCRT plans was $2.6 \pm 0.29$ minutes, $2.62 \pm 0.19$ minutes, $2.83 \pm 0.21$ minutes, and $2.52 \pm 0.19$ minutes, respectively. However, data obtained using QA for the total treatment times showed that

\section{Table 5. The evaluation of the thyroid gland-mean dose, and medulla spinalis-max dose measurements}

\begin{tabular}{l|l|l|l|l|l|}
\hline & VMAT & IMRT 5-field & IMRT 7-field & 3DCRT & Mean \pm SD \\
\hline & Mean \pm SD & Mean \pm SD & Mean \pm SD & $0.001 *$ \\
\hline Thyroid gland - mean dose & $20.54 \pm 4.83$ & $22.91 \pm 4.52$ & $21.05 \pm 3.42$ & $34.41 \pm 5.93$ \\
\hline Medulla spinalis - max dose & $24.96 \pm 2.93$ & $24.67 \pm 4.75$ & $26.88 \pm 3.45$ & $4.23 \pm 1.2$ \\
\hline VMAT: Volumetric modulated arc radiotherapy, IMRT: intensity-modulated radiotherapy, DCRT: dimensional conformal radiotherapy, SD: standard deviation
\end{tabular}

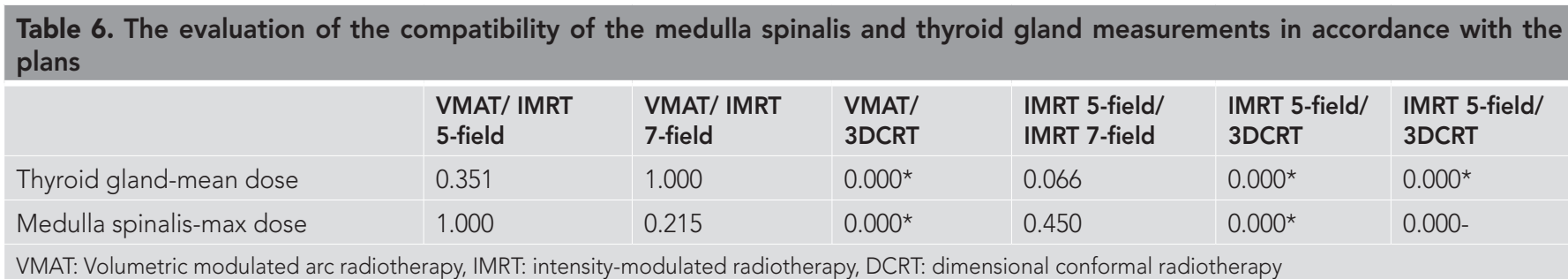

Table 7. The evaluation of the the means of the organs at risk (CC) measurements in accordance with the plans

\begin{tabular}{|c|c|c|c|c|c|}
\hline \multirow{2}{*}{ OAR volume } & VMAT & IMRT 5 field & IMRT 7 field & 3CRRT & \multirow{2}{*}{$p$} \\
\hline & Mean \pm SD & Mean \pm SD & Mean \pm SD & Mean \pm SD & \\
\hline V5 & $17.17 \pm 4.83$ & $16.54 \pm 4.52$ & $17.32 \pm 5.02$ & $11.03 \pm 3.93$ & 0.001 * \\
\hline V20 & $3.83 \pm 1.21$ & $7.66 \pm 1.89$ & $6.84 \pm 1.67$ & $5.31 \pm 1.44$ & $0.001 *$ \\
\hline V30 & $2.5 \pm 0.87$ & $3.15 \pm 1.11$ & $3.19 \pm 1.14$ & $4.2 \pm 1.35$ & $0.002^{*}$ \\
\hline
\end{tabular}

Table 8. The evaluation of the means of the monitor unit measurements in accordance with the plans

\begin{tabular}{|l|l|l|l|l|}
\hline \multicolumn{1}{|c|}{ VMAT } & IMRT 5-field & IMRT 7-field & 3CRRT & Mean \pm SD \\
\hline Mean \pm SD & Mean \pm SD & Mean \pm SD & P & 271 23.5 \\
\hline Monitor unit & $503 \pm 45.6$ & $792 \pm 114.4$ & $941 \pm 139.4$ & $0.001 *$ \\
\hline VMAT: Volumetric modulated arc radiotherapy, IMRT: intensity-modulated radiotherapy, DCRT: dimensional conformal radiotherapy, SD: standard deviation
\end{tabular}


the 3DCRT plans were superior. The total treatment times were as follows: VMAT plans, 3.69 \pm 0.31 minutes; 5-field IMRT plans, $6.92 \pm 0.61$ minutes; 7-field IMRT plans, $8.21 \pm 0.74$ minutes; and 3DCRT plans, $2.82 \pm 0.22$ minutes.

\section{DISCUSSION}

The primary aim of treatment of early-stage glottic larynx cancer is protecting the larynx function in particular, and protecting voice quality $(11,12)$. Therefore, RT has become the first treatment option in early-stage glottic larynx cancer, considering the relatively lower toxicity with good tumor control, and the organ-protective approach as compared to the surgical treatment $(13,14)$. Over time, RT techniques that reduce the potential adverse effects and morbidity risk have become research areas of interest $(15,16)$.

In early-stage glottic larynx cancer, RT treatment with two opposite fields enables greater tumor control. Patients have been treated with this method for years. However, there has been increased prevalence of atherosclerosis, carotid artery wall thickening, and cerebrovascular accident, as the carotid arteries are innately located in the treatment field. In recent years, the convenience of novel RT techniques such as IMRT and VMAT for treating earlystage glottic larynx cancer has been investigated. The main aim in these advanced technologies is to enable more conformal dose distribution in the target volumes and maximum protection of the surrounding tissues. Modern techniques with higher conformal RT planning and administration systems have the potential to decrease the early and late adverse effects that result from the limitation in tumor dose determination by reducing the dose to which the carotid arteries and surrounding tissues will be exposed. In addition, tumor control may be increased by enabling an increased dose to the target field using more conformal RT techniques

IMRT provides dose distribution that may create a concave/convex isodose line in the target tissues. The benefit of this modality is the possibility of reducing the early and late adverse effects by decreasing the distribution of high doses to the critical organs.

Many researchers have investigated VMAT for treating local advanced larynx cancer; however, the number of studies investigating VMAT for treating early-stage glottic larynx cancer is inadequate.

The publications on early-stage glottic larynx cancer in which VMAT is used are scarce $(17,18)$, as are comparison studies investigating VMAT and IMRT (19-22).

One advantage of VMAT is the shorter treatment time (23). There is no time loss in the form of a waiting period for the gantry to reach the expected state, as the radiation in VMAT is administered when the gantry is mobile. However, there is a waiting time for IMRT, which is a significant reason for the longer treatment periods $(23,24)$. Rosenthal et al. $(25)$ showed that the treatment times for IMRT and 3DCRT are similar (26).

Lower doses may be obtained in VMAT, as the shorter treatment time will reduce organ movement. Atalar et al. (22) reported that
VMAT had the shortest treatment time and lowest carotid artery dose.

However, the shortest treatment time recorded in the present study was for 3DCRT; VMAT had shorter treatment times compared to 5-field and 7-field IMRT. The advantage of the rapid treatment time is that the risk of missing the field is reduced by minimizing organ movement.

In the present study, double arc VMAT was preferred. Comparison studies of single and double arc VMAT have reported higher PTV involvement and critical organ protection rates in favor of double arc VMAT (27). Moreover, a study using double arc VMAT reported better parotid gland protection (28). However, discussion of the accurate VMAT technique is ongoing.

Maximum doses of decrease to the medulla spinalis may be enabled by identifying the angles of the IMRT regions from the anterior surface of the larynx; however, this increases the doses to the carotid artery $(22,29)$.

Although the medulla spinalis doses were within the tolerance doses for VMAT and IMRT, they were higher compared to 3DCRT $(p<0.001)$.

The primary aim of the present study was to identify the PTV involvement rate and to identify a limit dose for the critical organs (30). The lowest mean dose for the carotid arteries was, in the order of lowest to highest, from VMAT, IMRT, and 3DCRT. Thus, using VMAT would reduce the risk of cerebrovascular accident. However, it is unclear which dose limitations should be used in RT treatment of the carotid arteries. Therefore, it is possible that more prospective clinical studies will identify the clinical benefit of such dose reduction.

Rosenthal et al. (25) have recommended that decreased carotid artery doses are required, particularly in young patients with carotid artery pathology.

Martin et al. (31) found that a carotid artery vascular wall dose of $\geq 35-50$ Gy was significant. The values obtained in their study were higher than those of other studies. The reason could be the $7 \mathrm{~mm}$ safety margin given to the CTV in PTV identification.

Similar to carotid arteries, the thyroid gland is anatomically located in the neighboring region of the PTV. The use of RT for treating head-neck cancers may cause adverse effects such as hypothyroidism, Graves' disease, and various thyroid malignancies (32).

\section{CONCLUSION}

RT treatment of head-neck cancers gives rise to risk factors for carotid artery atherosclerosis, cerebrovascular accident, and thyroid dysfunction.

Here, using planning images, we devised 3DCRT, 5-field IMRT, 7-field IMRT, and VMAT plans for patients with early-stage glottic larynx cancer who were treated using only RT. Then, the plans were compared using dosimetric parameters. The 7-field IMRT was 
7. Braz DS, Ribas MM, Dedivitis RA, Nishimoto IN, Barros AP. Quality of life and depression in patients undergoing total and partial laryngectomy. Clinics 2005; 60: 135-42.

8. Lefebvre JL, Rolland F, Tesselaar M, Bardet E, Leemans CR, Geoffrois L, et al. Phase 3 randomized trial on larynx preservation comparing sequential vs alternating chemotherapy and radiotherapy. J Natl Cancer Inst 2009; 101: 142-52.

9. Chera BS, Amdur RJ, Morris CG, Kirwan JM, Mendenhall WM. T1N0 to T2N0 squamous cell carcinoma of the glottic larynx treated with definitive radiotherapy. Int J Radiat Oncol Biol Phys 2010; 78: 461-6.

10. Khuntia D, Hoffman HT, et al. Hypopharynx cancer. In: Halperin EC, Perez AC, Brady LW, editors. Perez and Brady's Principles and Practice of radiation Oncology. (5th ed) Philadelphia: Lippincott Williams \& Wilkins; 2008. pp. 958-74.

11. Caglar HB, Tishler RB, Othus M, Burke E, Li Y, Goguen L, et al. Dose to larynx predicts for swallowing complications after intensity-modulated radiotherapy. Int J Radiat Oncol Biol Phys 2008; 72: 1110-8.

12. Pfister DG, Laurie SA, Weinstein GS, Mendenhall WM, Adelstein DJ, Ang KK, et al. American Society of Clinical Oncology clinical practice guideline for the use of larynx-preservation strategies in the treatment of laryngeal cancer. J Clin Oncol 2006; 24: 3693-704.

13. Halperin EC, Perez CA, Brady LW. Perez and Brady's Principles and Practice of Radiation Oncology, 5thedn. Wolters Kluwer Health/ Lippincott Williams \&Wilkins, Philadelphia, PA, 2008.

14. Tong CC, Au KH, Ngan RK, Cheung FY, Chow SM, Fu YT, et al. Definitive radiotherapy for early stage glottic cancer by $6 \mathrm{MV}$ photons. Head Neck Oncol 2012; 4: 23.

15. Adams G, Burnett R, Mills E, Penniment M. Objective and subjective changes in voice quality after radiotherapy for early (T1 or T2, N0) laryngeal cancer: a pilot prospective cohort study. Head NeckOncol 2013; 35: 376-80.

16. Fujita M, Rudoltz MS, Canady DJ, Patel P, Machtay M, Pittard MQ, et al. Second malignant neoplasia in patients with T1 glottic cancer treated with radiation. Laryngoscope 1998; 108: 1853-5.

17. Verbakel WF, Cuijpers JP, Hoffmans D, Bieker M, Slotman BJ, Senan S. Volumetric intensity-modulated arc therapy vs. conventional IMRT in head-and-neck cancer: A comparative planning and dosimetric study. Int J Radiat Oncol Biol Phys 2009; 74: 252-9.

Ethics Committee Approval: Ethics committee approval was received for this study from the Ethics Committee of Okmeydanı Training and Research Hospital (approval number: 524, date: 25.10.2016).

Informed Consent: This is a retrospective study. Patient data were taken from the files.

Peer-review: Internally peer-reviewed.

Author Contributions: Surgical and Medical Practices - T.B.; Concept - T.B.; Design - T.B.; Data Collection and/or Processing - T.B.; Analysis and/ or Interpretation - T.B., B.D.; Literature Search - T.B., B.D.; Writing Manuscript - T.B.

Conflict of Interest: The authors have no conflict of interest to declare.

Financial Disclosure: The authors declared that this study has received no financial support.

\section{REFERENCES}

1. Jemal A, Siegel R, Xu J, Ward E. Cancer statistics, 2010. CA Cancer J Clin 2010; 60: 277-300.

2. Maier H, Dietz A, Gewelke U, Weidauer H. Tobacco and alcohol and the risk of head and neck cancer. The Clinical and Investigative Medicine 1992; 70: 320-7.

3. Harwood AR, Hawkins NV, Rider WD, Bryce DP. Radiotherapy of early glottic cancer. Int J Radiat Oncol Biol Phys 1979; 5: 473-6.

4. Rosier JF, Gregoire V, Counoy H, Octave-Prignot M, Rombaut P, Scalliet $P$, et al. Comparison of external radiotherapy, laser microsurgery and partial laryngectomy or the treatment of T1N0M0 glottic carcinomas: a retrospective evaluation. Radiother Oncol 1998; 48: 175-83.

5. Mendenhall WM, Parsons JT, Million RR, Fletcher GH. T1-T2 squamous cell carcinoma of the glottic larynx treated with radiation therapy: relationship of dose-fractionation factors to local control and complications. Int J Radiat Oncol Biol Phys 1988; 15: 1267-73.

6. Mendenhall WM, Werning JW, Hinerman RW, Amdur RJ, Villaret DB. Management of T1-T2 glottic carcinomas. Cancer 2004; 100: 1786-92.
18. Riegel AC, Antone J, Schwartz DL. Comparative dosimetry of volumetric modulated arc therapy and limited-angle static intensity-modulated radiation therapy for early-stage larynx cancer. Med Dosim 2013; 38: 66-9.

19. Kim ES, Yeo SG. Volumetric modulated arc radiotherapy sparing the thyroid gland for early-stage glottic cancer: a dosimetrical analysis. Oncol Lett 2014; 7: 1987-91.

20. Matthiesen $C$, Herman Tde L, Singh H, Mascia A, Confer M, Simpson H, et al. Dosimetric and radiobiologic comparison of 3D conformal, IMRT, VMAT and proton therapy for the treatment of early-stage glottic cancer. J Med Imaging Radiat Oncol 2015; 59: 221-8.

21. Camingue $P$, Christian $R, N g D$, Williams $P$, Amin $M$, Roniger $D L$. Comparison of external beam treatment techniques for T1-2, N0, M0 glottic cancers. Med Dosim 2012; 37: 221-4.

22. Atalar B, Gungor G, Caglar H, Aydin G, Yapici B, Ozyar E. Use of volumetric modulated arc radiotherapy in patients with early stage glottic cancer. Tumori 2012; 98: 331-6.

23. Gomez D, Cahlon O, Mechalakos J, Lee N. An investigation of intensitymodulated radiation therapy versus conventional two-dimensional and 3D-conformal radiation therapy for early stage larynx cancer. Radiat Oncol 2010; 5: 74.

24. White P, Chan KC, Cheng KW, Chan KY, Chau MC. Volumetric intensitymodulated arc therapy vs conventional intensity modulated radiation therapy in nasopharyngeal carcinoma: a dosimetric study. J Radiat Res 2013; 54: 532-45.

25. Rosenthal DI, Fuller CD, Barker JL Jr, Mason B, Garcia JA, Lewin JS, et al. Simple carotid- sparing intensity-modulated radiotherapy technique and preliminary experience for T1-2 glottic cancer. Int J Radiat Oncol Biol Phys 2010; 77: 455-61.

26. Scorsett M, Bignardi M, Clivio A, Cozzi L, Fogliata A, Lattuada P, et.al. Volumetric modulation arc radiotherapy compared with static gantry intensity modulated radiotherapy for malignant pleural mesothelioma tumor: a feasibility study. Int J Radiat Oncol Biol Phys 2010; 77: 942-9. 
27. Rotman M, Seidenberg B, Rubin I, Botstein C, Bosniak M. Aortic arch syndrome secondary to radiation in childhood. Arch Intern Med 1969; 124: 87-90.

28. Vanetti E, Clivio A, Nicolini G, Fogliata A, Ghosh-Laskar S, Agarwal JP, et al. Volumetric modulated arc radiotherapy for carcinomas of the oropharynx, hypopharynx and larynx: A treatment planning comparison with fixed field IMRT. Radiother Oncol 2009; 92: 111-7.

29. Chera BS, Amdur RJ, Morris CG, Mendenhall WM. Carotid-sparing intensity-modulated radiotherapy for early-stage squamous cell carcinoma of the true vocal cord. Int J Radiat Oncol Biol Phys 2010; 77: $1380-5$.
30. Osman SO, Astreinidou E, de Boer HC, Keskin-Cambay F, Breedveld S, Voet $P$, et al. IMRT for image-guided single vocal cord irradiation. Int J Radiat Oncol Biol Phys 2012; 82: 989-97.

31. Martin JD, Buckley AR, Graeb D, Walman B, Salvian A, Hay JH, et al. Carotid artery stenosis in asymptomatic patients who have received unilateral head and neck irradiation. Int J Radiat Oncol Biol Phys 2005; 63: 1197-205.

32. Garcia-Serra A, Amdur RJ, Morris CG, Mazzaferri E, Mendenhall WM Thyroid function should be monitored following radiotherapy to the low neck. Am J Clin Oncol 2005; 28: 255-8. 